\title{
A Pākehā journey towards bicultural practice through guilt, shame, identity and hope
}

\author{
Heidi Suzanne Crawford Manukau Institute of Technology, Auckland, New Zealand
}

\begin{abstract}
INTRODUCTION: For many social workers, aspects of their training and the development of competence are a growth journey that begins even before they may be aware of it starting, continues during training and throughout social workers' professional lives. One area that is of particular interest is bicultural practice, often an area that holds challenges for Pākehā practitioners for many reasons. The journey of understanding and growth towards being a social worker who practices biculturally is a long one that often, for Pākehā, starts in guilt and shame.

CONCLUSIONS: This article is a reflection of a Pākehā social worker, who shares her own personal journey through guilt and shame towards hope; hope that we can engage and journey in our bicultural practice to become a more compassionate, effective practitioner. As part of this reflection, the social worker shares her discovery of loss of identity as Pākehā and encourages other Pākehā to connect with who has gone before them in an attempt to understand self and understand others.
\end{abstract}

KEYWORDS: bicultural practice, biculturalism, Pākehā, identity, journey

\section{The journey}

As a Pākehā (New Zealander of European British descent) working in the social work profession, my attempt to work effectively in a bicultural manner can be encapsulated in the metaphor of a journey. This metaphor "acknowledges both ongoing process and the potential of many different routes" (Margaret, 2009, para. 22). The journey metaphor resonates with the process I am on in terms of becoming a practitioner who truly hopes to practice biculturally. I borrow a whakatauki from Ruwhiu, Ruwhiu and Ruwhiu that explains the reasoning for an introspective journey within myself; "e nohotiaana o waho rei roto he aha; our journey within to strengthen without" (2008, p. 16). This journey started from within, taking many routes and unlike many other journeys it is not about reaching a destination. In fact, one could say the destination is the journey itself. This journey must start with accepting and understanding the impact historically and currently of colonisation. Then it involves moving through the resulting feelings of guilt and shame because of the involvement of my ancestors and me. I acknowledge that not only am I involved by proxy to my ancestors historically but also through my continuation of colonisation because of my own blindness to white privilege. This journey requires a reflection of self and identity. Interestingly, in current literature it can be difficult to find personal detailed stories of this journey and the impact on sense of belonging and identity from a Pākehā social worker's perspective. In my experience, it can be difficult to share this journey as a Pākehā social worker for fear of getting it wrong, being offensive towards tangata whenua unknowingly, or even at times a sense of pride in that sharing the journey might highlight my own ignorance. The intention of sharing this journey is not to specifically outline bicultural practice in 
itself as that would be assuming a "one size fits all" perspective, which is an example of colonising behaviour. The purpose is to share the process of my journey, to encourage you to start or to continue on your own. At the very least, I invite you to contemplate the value of such an engagement.

The sharing my own journey of guilt, shame, hope and identity will hopefully encourage and challenge other Pākehā to start their journey or continue on it. Initially, the intention was to reflect on what bicultural practice looks like in my own work; however, it became a much deeper introspective wrestling with my personal sense of belonging, understanding of my own identity and questioning how I am of Aotearoa New Zealand. To be Pākehā on this journey we need to be challenged and to be questioned; we need to truly reflect and not enable the emotions centred on guilt and shame to become obstacles that we allow to stop us from moving forward. Although this is one Pākehā perspective I hope you feel challenged and encouraged to engage in the journey with honesty, integrity and the willingness to dig deep, and to explore areas of yourself that initially may cause some unease. By doing this, you will then connect with the hope your journey will bring not only for whānau Māori, but also for yourself and ultimately Aotearoa New Zealand.

For Māori who are reading these ponderings it is my hope you understand that my writing, reflection and thoughts come from a place of wanting to be on my journey of bicultural practice. I understand this is a never-ending journey with constant learnings and challenges. I strongly feel the call made by Reed (2016) who states that "change is going to require tauiwi [nonMāori] to step up and shrug off the invisible cloak of whiteness" (p. 5). Shrugging off this cloak is an ongoing part of my personal journey but one I am privileged to accept and that I view as a way of contributing to the hope of Aotearoa New Zealand. I hope you will forgive any unintentional errors or times when my thoughts may inadvertently come from that white privilege place as I acknowledge I am still reflecting, working, changing and wrestling with the challenges these present. I hope that my desire to make bicultural practice a central value in my work and, as Ruwhiu, Ruwhiu and Ruwhiu so eloquently describe it, my "heart mahi" (2008), can be heard.

That cloak of whiteness or white privilege is something that needs to be addressed intentionally by Pākehā. Many authors discuss the invisibility of that privilege in many different countries and environments, calling those who are unaware forward to recognise the position that this privilege gives them (Addy, 2008; Bennett, 2015; Delano-Oriaron \& Parks, 2015; GulatiPartee \& Potapchuk, 2014; Reed, 2016). Lang and Gardiner (2014), when discussing the bicultural imperative, state that the dominant race need to be aware of this privilege which Gulati-Partee and Potapchuk (2014) define as the "dominant, unquestioning standards of behaviour and ways of functioning ... [becoming] so normalised it is hard to see" (p. 27). Based on this knowledge, I echo Bennett (2015) by saying "ignorance is no longer an excuse" (p. 24).

That ignorance runs deeper than just being unaware of the privilege I have being Pākehā. It also encapsulates many Pākehā views and/or ignorance of Te Tiriti o Waitangi; I use this wording intentionally to refer to the te reo Māori version. To acknowledge the importance of Te Tiriti within the Aotearoa New Zealand context and its call to bicultural practice is to become part of a change agent identity. To grasp this identity, it is important that Pākehā can engage and find a way to challenge the idea that this is purely a Māori issue and that the concept of bicultural practice is only a Māori problem (Reed, 2016). For social workers within Aotearoa New Zealand, there needs to be an understanding that all social workers have a responsibility to not only engage with, but also to work actively to practice from a bicultural space. 
Bicultural practice is discussed by many people and professions, with differing understandings and opinions of what it looks like, or should look like. Coming from a Pākehā perspective, I found that it can be confusing as to what bicultural practice might look like in practice, in part because it was unknown. Mataira explains that,

Being bicultural is in as much about acknowledging ones daily triumphs as it is about overcoming self-doubt, and uncertainties. This all comes from knowing and accepting oneself. .... Knowledge and understanding is about adopting a very sensitive and caring attitude to life (1995, p. 10).

Being bicultural requires reflection in terms of knowledge and understanding of self within the Aotearoa context. We need to recognise the difficulties and pressures that come with putting yourself into the space of the unknown. This is done by using our thoughts and actions to adapt not only our way of being and working but, ultimately, even our understanding of self (Lang \& Katene, 2007; Mataira, 1995). This is more than just learning about another culture or ethnicity. It is about recognising the indigenous place of tangata whenua in Aotearoa and the need to work in a way that acknowledges, respects, understands, protects and walks alongside in a way that actively supports the rights and dignity of the indigenous people of the land without the paternalism that can so often be associated with these intentions. It is the thought, the processing, and the journey that is of even greater significance than the outcome itself (Walker, 2012). Taking part in this reflection, as well as knowing and accepting myself is an important part of the journey. It was within me that the biggest change was necessary. It was and is within myself that I must start.

Bicultural practice does not consist of a list that you can tick off to show when you have become the expert. We need to understand that bicultural practice "is not to be found in packaged boxes. Western world thinking leads us to believe compartmentalising things into frameworks makes it easy to look for answers to questions" (Mataira, 1995, p. 9). The Westernised version of understanding wants to define and create structure around concepts and ideas that make them explicit. This was definitely true of my own ways of thinking and understanding, especially in terms of trying to work out how I could get bicultural practice "right". I wanted to be told exactly what I could do to be a great practitioner, because I cared about good, evidencedbased practice. This attempt to "get it right" in terms of learning exactly what bicultural practice should look like is "riven with problems and oppressive politics ... [we need to] examine, explore and collaborate towards a place of authenticity" (Goldson \& Fletcher, 2004, p. 41). At the beginning of my journey, I was trying to force the understandings of te ao Māori into my own way of understanding, and my own context. Simply put, I was repeating behaviours of white privilege even while trying to get it "right" because I was also seeing te ao Māori as a composite world without tribal or whānau, hapu and iwi variation.

The most significant learning and challenge for me in terms of practicing biculturally came from kuia Māori I had the extreme privilege to work beside. These women supported me to a place of internally journeying, examining and exploring my own thoughts and ideas. Through true collaboration these kuia challenged me, questioned me and supported me in my place of confusion and vulnerability in my practice. Their patience and understanding, the way they looked through my own blustering and frustration and saw my heart mahi of wanting to "get it right". They engaged me in gentle and sometimes confronting conversations and opened my eyes to a way of being and a place of beginning to understand. I began to appreciate that all Māori are different; indeed the word tangata whenua means people of the land but not just any land 
rather specific areas of land. I was learning that the "right way" might work for one, but not be successful for others. The recognition that working biculturally was not a "one way fits all" approach seems like a simple understanding to reach, but this was a profound realisation on my journey.

One of the most precious moments in my own journey was when one of the social work kuia shared with me some of her frustrations in an open and gentle manner. She was frustrated that she always had to explain, to fight, to justify things Māori, and that she had to learn to play the Pākehā game. She shared that her heart still breaks at the blindness of many Pākehā social workers who have not really even begun the journey because of that invisible white privilege lying like scales over their eyes, but also because of their excuses and expressions of being frightened or angry about the challenge. It was not until this moment that I started to understand that my own colonising culture and white privilege was invisible to me. I began to understand that by allowing my own sense of uncomfortableness and fear to keep me from engaging in the journey, I was expecting Māori whānau and social workers to adapt to me. I have a choice to be bicultural; Māori do not.

Lang and Katene describe working together in a bicultural partnership by saying that this "bicultural waka [on its journey] is in new, turbulent and choppy waters" (2007, p. 40) and that the challenge is how to navigate that together. I have been privileged by those whānau Mãori who are willing to support my journey. Their graciousness and understanding of my heart mahi have supported me to start and continue my journey. I get lost, walk off the path and at times have not packed the right gear for that part of the journey; however, I am determined to learn, to process and to be open to change so that I can work out what I believe. I call to Pākehā who genuinely want to create a change for the better of our nation to begin the journey. If you are not prepared to learn alongside tangata whenua and actively engage in any knowledge that shared as part of that relationship, be mindful that books and models of practice will not support you to work biculturally. Do not be afraid to be in the place of not knowing, to ask questions and to be open. Remember that equally as important is to realise that what Mãori share is at the discretion of Māori people. Take up the mahi, sit alongside Māori and be an attentive listener and a genuine learner but respect the knowledge that is gained. Treasure the knowledge that is shared. The knowledge, together with sitting beside Māori and being attentive to that learnings this is one of the strongest ways, in my opinion, to understand and practice biculturally.

\section{Guilt and shame}

When first confronted by the impact that white settlers had on Aotearoa New Zealand, in particular the colonisation of the land, iwi, hapu and whānau, my first emotions and thoughts were of guilt and shame. Dominy (2002) discusses how deep the acts of colonisation were even in a physical sense on the whenua. He describes the colonisers' acquisition of land covered by bush, cutting the bush down and covering the space with grass. Even a simple thing like grass was an instrument of colonisation. Guilt and shame came into my awareness when I started to understand the extent of the damage that colonisation had caused. Literature shows that these feelings can be prevalent for Pākehā and other colonisers, especially when they are challenged by a sense of white privilege (Addy, 2008; Bell, 1999; Bennett, 2015; Delano-Oriaron \& Parks, 2015; Gulati-Partee \& Potapchuk, 2014; Lang \& Katene, 2007; Webber, McKinley, \& Hattie, 2013).Guilt and shame can evolve into even stronger emotions like resentment, fear and anger. Pākehā can feel stigmatised "as the dominant colonial oppressor, the shamed progenitor of past injustices guilty by ancestral injustices" which leaves many feeling "a space of fear, resentment, contestation and perceived fear of loss" (Bidois, 2013, p. 148). This can result in 
Pākehā ignoring the journey and furthering the idea of white privilege by believing that the journey is not a necessary one, suspending any engagement because of the fear.

My next step was trying to justify the reasons settlers acted the way they did. Thoughts of how those people long ago were not necessarily my ancestors echoed in my ears; whispers of, "that has nothing to do with me that was generations ago". These thoughts were expressed in Bell's (2009) research with Pākehā teens with many teens feeling like colonisation was not of the present and was not relevant to them now. I almost allowed those feelings of guilt and shame to become barriers to truly digging deep into the thinking around colonisation in Aotearoa New Zealand. To be told that I am a coloniser initially made me angry and left me wondering how I, as a good and caring person, could be considered a coloniser.

The reason I ruminate articulate these thoughts is because I know I am not alone. Many Pākehā I have spoken with share these thoughts. Some even share the very strong opinions voiced by Don Brash in his infamous speech in Orewa in 2004, entitled "Nationhood" and where he stated that New Zealanders should be considered "one people". Callister (2015), echoes these thoughts writing that, "if we really want to minimise complexity, then one alternative is to revisit the "deep history" data in order to embrace the notion that we are all "one people" with shared ancestral roots that stretch all the way back to Africa" (p. 5). I am embarrassed by these expressions of those in powerful positions in our country but I also recognise that these are expressions of white privilege. Thoughts like this are why the discussion of colonisation, white privilege and a call to bicultural practice are still happening constantly today. The words of "one people, one nation" (Bidois, 2013; Kirkwood, Liu, \& Weatherall, 2005) when spoken from a majority, western, white privileged way of thinking is a form of continual colonisation. To say we are "one people" is insinuating that everyone must be the same. This then raises the question of who are we to be the "same" as? Will it be those in power? Those with the loudest voice? Those that are the "norm"? It is without argument that in Aotearoa New Zealand this would be Pākehā. This puts Mãori in the position of having to adapt to the white, "normal" way of being, which is again the hegemonic voice of colonisation rearing its head (Mulqueeney, 2012;

Rangihau, 2008; Webber, 2006). This happens not just in terms of culture and identity but also in economics and law (Hilliard, 2010; Kirkwood et al., 2005; Lyons, Madden, Chamberlain, \& Carr, 2010). We, as Pākehā, reinforce the white privilege, by allowing current patterns and inequalities to happen, by saying nothing, doing nothing or seeing nothing (Lyons et al., 2010). This is evident not only in my personal reflection but also in studies with Pākehā participants. In these studies, Pākehā acknowledge the past injustices and are happy for Māori to have a way of being, which in itself could be seen as paternalistic, however in terms of how funding is given and sharing of resources the desire to work in partnership seems to disappear (Bell, 1999; Bell 2009; Sibley \& Liu, 2004).

I realised, however, that it was not only those feelings of guilt and shame that affected my understanding of my own role within white privilege but their potential to become my reasoning for ending my journey there. Bidois (2013) makes a strong and important statement, that "in order to reverse and disrupt continued acts of psychological, cultural and social violence, one must turn the gaze back upon one's self; a look that unsettles and unease's the dominate subject position through the gaze of alternaity" (p. 151). To be able to move forward I needed to turn the gaze back on myself to look at alternative positions. I needed to open myself up to "use words like brutality, indifference, violence, wrenching, snatching, seizing of land: intentional destruction, undermining, disruption, stamping out 
of language and culture" (Nairn, 2009, para, 13). To be on the journey, I need to think deeper and be open to changing myself.

Turning the gaze back upon myself, I started to understand that I was beginning to have questions about my own sense of identity and belonging. Bell (2009) discussed the need for Pākehā to engage with our history, the need to reflect on how we got here, on what happened and is happening in Aotearoa for Mãori. To do this, I had to "learn something crucial about being Pākehā in the present" (Bell, 2009, p. 156). I needed to learn about who I am and where I fit. My journey took an unexpected turn when I started contemplating that if Māori are tangata whenua (people of the land) with their bones lying here in Aotearoa New Zealand and they could whakapapa (identify their relationship with the world, with people and with life) to the whenua (land), what does that mean about my own sense of belonging? I was left asking; what did that make me? My own family has been here in Aotearoa New Zealand for many generations. If Māori lay claim to Aotearoa, then where was my claim, where did I belong, did this mean I am not a part of this country that I love?

\section{Pākehā identity}

Ko Jessie Osborne toku waka (1876)

Ko Isle of Arran toku maunga

Ko Irvine toku awa

Ko Scotland, Ireland, England toku iwi

Ko Greg Crawford toku matua

Ko Carlene Amos toku whaea

Ko Heidi ahau

One catalyst for reflecting on my own sense of identity and belonging is the wondering that many Pākehā share, particularly those whose families have been in Aotearoa New Zealand for many generations. The question of Pākehā identity expressed so well by the late Comedian, Ewan Gilmore who is quoted as saying, "My family has been in New Zealand for 150 years, on both sides of the family. I have no claims on anything in Britain, and there has been no Māori blood in the family, so I have no identity" (cited in Bell, 2009, p. 147). Bell's research goes on to show that for many young Pākehā there is a strong sense of lack of belonging, roots and identity (2009). Lyons et al. (2010), who discuss Bell's research, reflected that young Pākehā feel a "weak claim to place and a relative lack of belonging [that] are bound up with constructions of national identity" (p. 16).

One key step in this journey was my choice of wording in terms of naming my national identity. Putting European on census forms felt alienating because my family has been in this country for generations. In addition, I am from Scottish, Irish and English roots, not continental of Europe. Writing "New Zealander", as many have chosen to do, also did not feel right. This phrasing felt like I was coming from a sense of white privilege assuming "one people" by applying a title that intends to name everyone in Aotearoa as the same. As someone who delights in the depth that diversity brings to our nation, I was strongly opposed to using this wording. I value the ethnicity, culture and language that each person brings as part of their own identity. To write "New Zealander" would also ignore the diversity of Aotearoa. The outcome for me was to adopt the te reo Māori word, Pākehā, as many others before me have done (Kirkwood et al., 2005). This choice was a deliberate one and a key turning point in my journey.

I feel that choosing Pākehā, a te reo Māori title, acknowledged that while this is not the land that I belong to, it is still the land that I belong to. It took a long time to make sense of a statement that initially seems contradictory, but which summarises my sense of place and my journey. I cannot ignore where the bones of my ancestors lie, that is important to who I am. I am proud of my heritage, but I also cannot ignore where my feet currently stand. When discussing the stage plays of Henderson, who writes about Pākehā and their connection to their land and farms in Aotearoa New Zealand, Warrington shares that 
"Henderson's expression of understanding Tūrangawaewae, a place to stand, [is] rooted in the politics of "home", a passionate and emotional connection associated with memory and self-worth" (2009, p. 76). Rangihau (2008) describes tūrangawaewae as:

that emotion that the land has for Māori and the tie is something you can use, not because the Māori see land as something you can use, nor as they do see it now as being something negotiable, no he sees the land as the place from whence he has come - mother earth and father sky (p. 7).

My journey led me to consider which land was to be my tūrangawaewae.

This question of what land is my tūrangawaewae is one I still struggle with as it continues to lead me to question my own identity. This passionate and emotional connection is one that I have for more than one land. The whenua of Aotearoa New Zealand calls to me more strongly than the whenua of Papua New Guinea, where I was raised as a child of missionary parents. It calls even more than the whenua of Scotland, the land in which my own ancestors drank, ate, lived and fought. My journey has led me to choose the title Pākehā because it names me as someone who belongs in both worlds. Furthermore, my journey has led me to consider the lives of those who have gone before me in Scotland and Ireland, who have worn their tartan, fought for their tribes and lived on the hills and mountains of those whenua. A whenua and people that hold so many similarities to Aotearoa. They are my ancestors whose maunga (mountain) and awa (river) are beside the seaside, the seaside that carries the sound of the waves and smell of the salt on the wind. I do not forget the connection I have with that land and this one.

\section{Hope}

The journey I am on does not end in guilt and shame. I will not allow it. As Lang and Katene (2007) describes, it is "important that while I accept the inevitability of repeat colonisation, I am not guilt ridden to a point of torpor" (p. 36). I will not stand still. I will continue because I have my own identity and that of tangata whenua to consider. Guilt and shame cannot be the end. To move forward:

it is important to recognise that it is the acknowledgement of the breaches, the expression of remorse, the commitment not to transgress further, and the will to establish and maintain group processes to redress the state of imbalance ... not a denial or defence of those unjust actions (Rata, Liu, \& Hanke, 2008, p. 29).

This is the start; to commit to being on the journey and creating this redress and change, not only in my practice, but also in my understanding of the world.

My own understanding and valuing of bicultural practice is a relatively new thing. I am on this journey and realising that those around me are desperately hoping that I will see the way, and continue walking forward. This journey alongside whānau Māori is a process where I "must not look at the past with fear, or upon acts of the past with shame; nor should [I] vilify and alienate others in the name of retribution or justice. Instead Māori and Pākehā must work together at the boundaries of identity and difference" (Bidois, 2013, p. 153). Working biculturally is not about me being Māori or claiming the same rights as Māori who are the tangata whenua of this beloved land. It is about the desire to be recognised as people who have unique identities, with specific responsibilities, occupying collaborative spaces, to no longer be divided but live together as adopted whānau or whānau whānui, not connected by whakapapa but by intention, to join our waka together in convoy on this journey (Bell, 2009). The journey of hope is about my own heart mahi, which calls me to genuinely work towards making a difference in the language and actions of not only myself, but also those around me. "Indeed it is what is in our hearts that matters" (Lang \& Katene, 2007, p. 38). 
It is vital that Pākehā realise how deeply imbedded colonisation and white privilege are. We need to understand that for Māori, when Pākehā make an approach, there is hesitancy, a wondering of why we come and what we want. Only by meeting and being together can Māori "accept the person as wanting to learn out of a genuine desire to do so" (Rangihau, 2008, p. 10). Meeting and being together is the beginning of listening. However, it is vital to realise that for Māori it can feel that although some say they are listening to what is being expressed in terms of change need, listening with a lack of action does not show a commitment to making the changes (Rata et al., 2008). The journey for me is part of my action.

Actions are what make a difference. Consedine and Consedine (2012) share important steps in the restoration process beginning with a genuine apology and ending in a commitment to making a change. My hope is that if more and more Pākehā are truly open to this journey, we can join with whānau Māori to create a new narrative for this land. For this to happen, "apologies must be embedded in the social narratives and lived experiences of the people of the nation" (Celemajer \& Kidman, 2012, p. 243). We need to make this part of our greater society. Part of this journey starts within self, but also represents a call to wider society to make change. I hope for this future. To begin my own part, I accept responsibility for the actions of my ancestors and my people along with the damage and pain caused. I also accept responsibility for my own actions that come from that invisible sense of white privilege and continue to be hidden and not so hidden actions of colonisation. I share my heartfelt apology for those that have gone before me, as well as for my own actions and inactions. I will do my best to repair and restore those things that have been lost. I am making a stand to say I am a coloniser who sits within a space of white privilege but I no longer want to be so. I want to be one who truly joins hand in hand with whānau Māori within this beautiful land, and works towards living together in respect, authenticity and partnership.
My hope is that this journey will take me towards bicultural wisdom or "a profound sense of knowing two compassionate worlds and using the knowledge and principles of both for the betterment of society as a whole" (Mataira, 1995, p. 10). My heart mahi is to be part of the journey to create a new understanding. Together Māori and Pākehā can build a new narrative for the land of Aotearoa New Zealand, one of healing and reconciliation (Celemajer \& Kidman, 2012).

The journey on this waka has allowed me to hold an incredible sense of hope for four reasons:

First, I have come to know myself and to make conscious decisions about the reasons for my use of words and actions. This is true not only in my practice as a social worker, but also in terms of my life as a whole.

Second, my hope for generations of Pākehā is that they also begin and continue the journey to search for what makes up their identity so as to discover a deeper, personal sense of who they are and where they belong.

Thirdly, I strongly believe that if Pākehā are open to investigating white privilege and continued acts of colonisation, the recognition of the guilt and shame that come with it, as well as the understanding that these things are still alive and thriving in our everyday being, will encourage Pākehā to accept responsibility and commit to change.

Lastly, when one is on this journey one becomes much more aware of Maori worldviews and ways of being, Maori knowledge, ideas about health and wellbeing, and the worth of all of these factors in social work practice. This learning helps us to not only better support whānau Māori, but also to become a much more aware and more sensitive practitioner for all those with whom we journey. It is important that we do not focus on what we can take, but what we can learn. We must, therefore: not perpetuate privilege but recognise the privilege of relationships; not focus on 
the explicit but be open to developing our understanding of the implicit and that the journey of reflection and is never ending. These principles are the essence of bicultural social work practice.

From the language of my ancestors, the language of the tangata whenua of my beloved Aotearoa and my own tongue,

Tairiscint liom tú go maith.

$$
\begin{array}{r}
\text { E mea i a koe te pai. } \\
\text { I bid you well. }
\end{array}
$$

\section{References}

Addy, N. (2008). White privilege and cultural racism. New Zealand Journal of Counselling, 28(1), 10-23.

Bell, A. (1999). Styling the other to define the self: A study in New Zealand identity making. Journal of Sociolinguistics, 3(4), 523-541.

Bell, A. (2009). Dilemmas of settler belonging: Roots, routes and redemption in New Zealand national identity claims. The Sociological Review, 57(1), 145-162.

Bennett, B. (2015). 'Stop deploying your white privilege on me!'Aboriginal and Torres Strait Islander engagement with the Australian Association of Social Workers. Australian Social Work, 68(1), 19-31.

Bidois, V. (2013). A genealogy of cultural politics, identity, resistance. Alternative: An International Journal of Indigenous Peoples, 9(2), 142-154.

Callister, P. (2015). The New Zealand 'melting pot': An opinion piece. Auckland, New Zealand: Callister \& Associates.

Celemajer, D., \& Kidman, J. (2012). Embedding the apology in the nations identity. Journal of Polynesian Society, 12(3), 219-242.

Consedine, R., \& Consedine, J. (2012). Healing our history: The challenge of the Treaty of Waitangi. Auckland, New Zealand: Penguin Random House.

Delano-Oriaron, O. O., \& Parks, M. W. (2015). One black, one white: Power, white privilege, \& creating safe spaces. Multicultural Education, 22(3-4), 15-19.

Dominy, M. D. (2002). Hearing grass, thinking grass: Post colonialism and ecology in Aotearoa New Zealand. Cultural Geographies, 9, 15-34.

Goldson, J., \& Fletcher, T. R. (2004). Training for bicultural intervention with families. New Zealand Journal of Counselling, 25(2), 33-43.

Gulati-Partee, G., \& Potapchuk, M. (2014). Paying attention to white culture and privilege: A missing link to advancing racial equity. Foundation Review, 6(1), 25-38. doi:10.9707/1944-5660.1189

Hilliard, C. (2010). Licensed native interpreter: The land purchaser as ethnographer in early-20th-century New Zealand. The Journal of Pacific History, 45(2), 229-245.

Kirkwood, S., Liu, J. H., \& Weatherall, A. (2005). Challenging the standard story of indigenous rights in Aotearoa New Zealand. Journal of Community \& Applied Social Psychology, 15(6), 493-505.
Lang, S. K., \& Gardiner, B. D. (2014). As they like it - culturecentred counsellor education in the context of Aotearoa New Zealand: A play on bicultural pluralism. British Journal of Guidance \& Counselling, 42(1), 73-85.

Lang, S. K. W., \& Katene, K. (2007). Tikanga and ethics: A dialogical encounter of two cultures. New Zealand Journal of Counselling, 27(1), 33-42.

Lyons, A. C., Madden, H., Chamberlain, K., \& Carr, S. (2010). 'Its not really us discriminating against immigrants, its more telling people how to fit in': Constructing the nation in immigration talk in New Zealand. Journal of Community \& Applied Social Psychology, 21,(1) 14-27.

Margaret, J. (2009). Reflections on the past - learning in social movements. Experience in the Pākehā Treaty Workers' movement. Retrieved from http://www.trc. org.nz/understanding-learning-social-movementsstudy-learning-p $\% \mathrm{C} 4 \% 81$ keh\%C4\%81-treatyworkers\%E2\%80\%99-movement

Mataira, P. (1995). Bicultural wisdom: Navigating the bicultural seas. Social Work Review, VII(1), 9-10.

Mulqueeney, N. (2012). 'Tumeke bro?' A personal reflection of a male white counselor working with male Māori tamariki. New Zealand Journal of Counselling, 31(1), 56-67.

Nairn, M. (2009). National issues: Pākehā languaging around Te Tiriti. Retrieved from http://www.trc.org.nz/sites/trc. org.nz/files/P\%C4\%81keh\%C4\%81\%20languaging.pdf

Rangihau, J. (2008). Māori culture today. Te Komako, 4, 3-12.

Rata, A., Liu, J. H., \& Hanke, K. (2008). Te arahohourongo (The path to peace): Māori conceptualisations of intergroup forgiveness. New Zealand Journal of Psychology, 37(2), 18-30.

Reed, K. (2016). Frances Rutherford Lecture 2015. Possibilities for the future: Doing well together as agents of change. New Zealand Journal of Occupational Therapy, 63(1), 4-13.

Ruwhiu, P. T., Ruwhiu, L. A., \& Ruwhiu, L. L. H. (2008). Te tatoukupenga: Mana tangata supervision. A journey of emancipation through heart mahi for healers. Te Komako, 4, 13-34.

Sibley, C. G., \& Liu, J. H. (2004). Attitudes towards biculturalism in NZ: Social dominance \& Pākehā attitudes towards the general principles and resourcesspecific aspects of bicultural policy. New Zealand Journal of Psychology, 33(2), 88-99.

Walker, S. (2012). The teaching of Māori social work practice and theory to a predominantly Pākehā audience. Aotearoa New Zealand Social Work, 24(3\&4), 65-72.

Webber, M. (2006). Explorations of identity for people of mixed Māori/Pākehā descent: Hybridity in New Zealand. International Journal of the Diversity, 6(2), 7-13.

Webber, M., McKinley, E., \& Hattie, J. (2013). The importance of race and ethnicity: An exploration of New Zealand Pākehā, Māori, Samoan and Chinese adolescent identity. New Zealand Journal of Psychology, 42(2), 17-28. 